\title{
Sex reassignment: outcomes and predictors of treatment for adolescent and adult transsexuals
}

\author{
YOLANDA L. S. SMITH*, STEPHANIE H. M. VAN GOOZEN, ABRAHAM J. KUIPER \\ AND PEGGY T. COHEN-KETTENIS \\ Department of Child and Adolescent Psychiatry, University Medical Centre Utrecht, The Netherlands; \\ Department of Medical Psychology, VU University Medical Centre, Amsterdam, The Netherlands
}

\begin{abstract}
Background. We prospectively studied outcomes of sex reassignment, potential differences between subgroups of transsexuals, and predictors of treatment course and outcome.

Method. Altogether 325 consecutive adolescent and adult applicants for sex reassignment participated: 222 started hormone treatment, 103 did not; 188 completed and 34 dropped out of treatment. Only data of the 162 adults were used to evaluate treatment. Results between subgroups were compared to determine post-operative differences. Adults and adolescents were included to study predictors of treatment course and outcome. Results were statistically analysed with logistic regression and multiple linear regression analyses.
\end{abstract}

Results. After treatment the group was no longer gender dysphoric. The vast majority functioned quite well psychologically, socially and sexually. Two non-homosexual male-to-female transsexuals expressed regrets. Post-operatively, female-to-male and homosexual transsexuals functioned better in many respects than male-to-female and non-homosexual transsexuals. Eligibility for treatment was largely based upon gender dysphoria, psychological stability, and physical appearance. Maleto-female transsexuals with more psychopathology and cross-gender symptoms in childhood, yet less gender dysphoria at application, were more likely to drop out prematurely. Non-homosexual applicants with much psychopathology and body dissatisfaction reported the worst post-operative outcomes.

Conclusions. The results substantiate previous conclusions that sex reassignment is effective. Still, clinicians need to be alert for non-homosexual male-to-females with unfavourable psychological functioning and physical appearance and inconsistent gender dysphoria reports, as these are risk factors for dropping out and poor post-operative results. If they are considered eligible, they may require additional therapeutic guidance during or even after treatment.

\section{INTRODUCTION}

The phenomenon of transsexualism refers to individuals who are born with the normal sexual characteristics of one sex, but have the irrefutable conviction of belonging to the other.

Nowadays, many professionals who specialize in the treatment of transsexuals regard the

* Address for correspondence: Prof. Dr P. T. Cohen-Kettenis, VU University Medical Centre, Department of Medical Psychology, P.O. Box 7057, 1007 MB Amsterdam, The Netherlands.

(Email: pt.cohen-kettenis@vumc.nl) conviction of transsexuals as belonging to someone of the other sex as authentic and, consequently, their wish for a sex change to be justified. The recommended procedure of the Harry Benjamin International Gender Dysphoria Association (Meyer et al. 2001), an international professional organization regarding transsexualism, is to approach the referral for sex reassignment (SR) in two phases. In the first phase, a DSM-IV diagnosis (APA, 1994) is made. In addition, the eligibility of the patient to move on to the second phase, the Real-life 
Table 1. Progression in the SR procedure and matching sample sizes used in analyses

\begin{tabular}{lcccccr}
\hline \hline SR & $\begin{array}{c}\text { Diagnostic } \\
\text { 1st phase } \\
\text { procedure }\end{array}$ & $\begin{array}{c}\text { Not referred } \\
\text { for 2nd phase } \\
\text { (Non-starters) }\end{array}$ & $\begin{array}{c}\text { Referred for, } \\
\text { started, continued } \\
\text { 2nd phase } \\
\text { (Starters) }\end{array}$ & $\begin{array}{c}\text { Referred for, } \\
\text { started, dropped out } \\
\text { 2nd phase } \\
\text { (Drop-outs) }\end{array}$ & $\begin{array}{c}\text { Referred for, } \\
\text { completed } \\
\text { SR surgery } \\
\text { (Completers) }\end{array}$ & $\begin{array}{c}\text { 1-4 years after } \\
\text { SR surgery } \\
\text { (Follow-up) }\end{array}$ \\
\hline MFs & 220 & 74 & 146 & 29 & 117 & 71 \\
FMs & 105 & 29 & 76 & 5 & 184 & 64 \\
Included & 325 & 103 & 222 & 34 & 158 \\
\hline \hline
\end{tabular}

a In the first phase a DSM diagnosis is made and eligibility is assessed for starting hormone treatment and the Real-life Experience.

b In the second phase hormone treatment and the Real-life Experience is started.

Experience (RLE), is assessed. In this phase the applicant's ability to live in the desired role and its consequences, and the strength of the desire for SR are evaluated. If the social role change during the RLE, which is usually supported by hormonal therapy, results in a satisfactory outcome, the applicant will be referred for surgery (see Table 1).

Although SR is presently regarded as effective in treating transsexualism, the most extreme end of Gender Identity Disorder (GID) (Pfäfflin \& Junge, 1992, 1998; Eldh et al. 1997; CohenKettenis \& Gooren, 1999; Rehman et al. 1999; Meyer et al. 2001; Smith et al. 2001, 2002; Day, 2002; Lawrence, 2003), prospective studies are needed to enhance knowledge about the benefits and limitations of SR. In spite of strict prior selection and counselling during treatment, an estimated $1-2 \%$ of those treated express regrets about SR (Pfäfflin, 1992; Pfäfflin \& Junge, 1992, 1998; Kuiper \& Cohen-Kettenis, 1998). Considering the invasive and irreversible treatment of SR, it is imperative to try and prevent post-operative regret. This requires the identification of predictors of regret or poor postoperative functioning. In some follow-up studies different factors are proposed as influencing the outcomes of SR negatively (e.g. Wålinder et al. 1978; Spengler, 1980; Lothstein, 1982; Lundström et al. 1984; Blanchard, 1985; Lindemalm et al. 1987; Blanchard et al. 1989; Ross \& Need, 1989; Pfäfflin, 1992; Pfäfflin \& Junge, 1992; Kuiper \& Cohen-Kettenis, 1998; Landén et al. 1998). These factors lie in the area of psychological functioning, sexual orientation, age at assessment, onset age of gender dysphoria, family history and support, professional support during SR, and surgical outcomes. However, the quality of the few existing followup studies is rather poor given their mostly retrospective nature. Sound prospective studies are needed to identify predictors of postoperative functioning more consistently and reliably.

In the present large-scale prospective followup study, we investigated two separate though related topics: the outcomes of SR and the prediction of favourable or poor outcomes. Therefore, we first evaluated whether transsexuals actually improve in important areas after SR, and confirm some of the beneficial effects of SR previously established in the mostly retrospective follow-up studies (e.g. Mate-Kole et al. 1990; Day, 2002; Lawrence, 2003). Secondly, we studied differences between sexes [male-tofemales (MFs) and female-to-males (FMs)] and subtypes (homosexuals and non-homosexuals) in various areas of functioning (e.g. gender dysphoria, body dissatisfaction, physical appearance, psychological functioning) after SR. To our knowledge, subtype differences have not yet been prospectively studied. These research questions were, however, only studied in adult transsexuals, because the adolescent results have been published previously (Smith et al. 2001, 2002). Post-operatively, feelings of regret, evaluation of treatment, satisfaction with surgical results, social and sexual functioning were evaluated.

The other topic concerned predictors of the course and outcomes of SR. We examined which factors clinicians based their referral on for SR. The factors were age, sex, sexual orientation, onset age of gender dysphoria, gender dysphoria in childhood and at application, social support, body dissatisfaction, physical appearance and psychological functioning. Finally, we examined which factors predicted treatment course (i.e. dropping out), post-operative functioning, and treatment satisfaction. 


\section{METHOD}

\section{Subjects}

A total of 325 consecutive adolescents and adults, who applied for SR at VU University Medical Centre in Amsterdam (VUmc) or University Medical Centre Utrecht (UMCU), participated. Of these, 222 (146 MFs, 76 FMs) started hormone treatment: the 'starter' group. Twenty-nine MFs and 5 FMs stopped hormone treatment: the 'drop-out' group. The group who completed SR consisted of 188 patients (117 MFs, 71 FMs): the 'completer' group. The group who never started hormone treatment consisted of 103 patients (74 MFs, 29 FMs). Pre-test data from this 'no-starter' group varied from 89 to 103 . At follow-up, some participants had moved abroad, while others were untraceable, which resulted in 158 (94 MFs, $64 \mathrm{FMs}$ ) participants who were interviewed. Follow-up data ranged between 136 and 158 because not all participants were willing or able to take part in both an interview and a questionnaire session (Table 1).

To examine the outcome issue we used data of 162 adults. Pre-test data were obtained from all adults (104 MFs, 58 FMs; 94 homosexuals, 68 non-homosexuals). Follow-up interview data were gathered from 126 adults (i.e. $78 \%$; 77 MFs, 49 FMs; 71 homosexuals, 55 nonhomosexuals). Questionnaire data for different measures fluctuated from 101 to 126. Since SR patients do not undergo all possible operations, data on breast augmentation were gathered from 52 MFs (21 homosexuals, 31 non-homosexuals), and on metaidoioplasty or phalloplasty from 10 FMs (4 homosexuals, 6 non-homosexuals). Scores on the Appraisal of Appearance Inventory were obtained from 57 adults.

\section{Instruments}

\section{Biographical data}

The Biographical Questionnaire for Transsexuals, a semi-structured interview, contains 211 items on variables, such as cross-gender feelings and behaviour, social and sexual contacts (Verschoor \& Poortinga, 1988; Doorn et al. 1994). The following items were used: sex (MF or FM), onset age of cross-gender feelings, childhood GID symptoms (11 items, see below), age at application, and sexual orientation.
Concerning this last item, participants who exclusively reported a homosexual preference (MFs sexually attracted to biological males; FMs to biological females) were included in the homosexual group. Participants with an asexual, heterosexual, and/or bisexual preference were included in the non-homosexual group. Age at the start of hormone therapy and surgery were obtained from medical files.

The GID in Childhood Scale was constructed from the Biographical Questionnaire for Transsexuals (Verschoor \& Poortinga, 1988; Doorn et al. 1994) to measure the self-reported presence of GID symptoms in childhood. There are 11 items (Cronbach's $\alpha=0 \cdot 81$ ) concerning the strong wish to be of the opposite sex in early childhood, cross-gender appearance of the child, cross-dressing, play and peer preference, and cross-gender behaviour. Because of differences in the numbers and types (i.e. quantitative versus qualitative) of response categories, answers were dichotomized, resulting in a total score ranging between 0 and 11 , with the higher scores indicating more childhood GID symptoms.

The Social Support Scale. This scale has 10 items enquiring about the patient's eight closest acquaintances (Van Tilburg, 1988). Scalability coefficient $H$, calculated by means of a Mokken analysis (Molenaar, 1982) and calculated for all relationships together, was 0.38. Sumscores range from 0 to 160 , with the higher scores indicating more support.

Gender dysphoria. This was measured with the Utrecht Gender Dysphoria Scale, containing 12 items on which the subject rated agreement on a 5-point scale. Scores range from 12 to 60 . Higher scores indicate more gender dysphoria (Cohen-Kettenis \& van Goozen, 1997).

Body dissatisfaction. A Body Image Scale (Lindgren \& Pauly, 1975), adapted for a Dutch sample (Kuiper, 1991), was used. There are 30 items divided into three subscales: primary and secondary sex characteristics, and neutral body parts, with higher scores representing more dissatisfaction.

Physical appearance. On the Appraisal of Appearance Inventory three independent observers 
(the diagnostician, a nurse, the researcher) rated the subject's appearance on 14 five-point scales of gender compatibility. The characteristics were: hair, facial hair, larynx, voice, figure, height, skin, hands/feet, muscularity, chin, nose, jaw, speech, and gestures/movement. Lower scores reflect a better appearance in matching the new gender. Intra-class correlation coefficients between observers for each of the 14 items ranged from $0 \cdot 68$ to $0 \cdot 79$.

Psychological functioning. The Dutch Short MMPI (Luteyn et al. 1980) contains 83 items measuring Negativism, Somatization, Shyness, Psychopathology, and Extroversion. Higher scores indicate more dysfunction on the first four scales but less on Extroversion.

The Dutch version of the Symptom Check List (Derogatis et al. 1973; Arrindell \& Ettema, 1986) has 90 items enquiring about recent complaints. Subscales are: Agoraphobia, Anxiety, Depression, Somatization, Obsession/ Compulsion, Suspicion, Hostility, and Sleeping problems. The total score for Psychoneuroticism ranges from 90 to 450 . Higher scores indicate more psychological instability.

Treatment evaluation and post-treatment functioning. To evaluate post-operative functioning 13 items measured post-operative functioning and (dis)satisfaction (e.g. with questions about treatment, regret, social and sexual functioning, and social experiences) (Doorn et al. 1996). Patients also completed a questionnaire about the functioning of vagina/penis and breasts (augmentation or removal), and surgical satisfaction (Cohen-Kettenis \& van Goozen, 1997).

Post-operative Functioning Scale. Twenty-one items (Cronbach's $\alpha=0 \cdot 87$ ) measured postoperative functioning and satisfaction with SR (Doorn et al. 1996) and resulted in a single score with higher scores reflecting worse functioning and more dissatisfaction. (See Journal's website for Appendix with specific items.)

\section{Procedure}

The GID in Childhood Scale and the Social Support Scale were used at pre-test. Gender dysphoria, body dissatisfaction, physical appearance and psychological functioning were assessed before and after SR to measure change. The remaining instruments were administered at follow-up.

Except for the GID in Childhood Scale, the Social Support Scale, and the Post-operative Functioning Scale, all instruments were used to examine the issue of outcome. All instruments administered at pre-test were used to investigate predictors of eligibility for and drop-outs of SR. Follow-up data of the 'completer' group were used to develop the Post-operative Functioning Scale, investigating predictors of outcomes of SR.

Pre-test data were gathered during the first diagnostic procedure after the first interview. Follow-up data were gathered at least 1 year after surgery. Sessions took between 2 and 3 hours. The Ethics Committees of the UMCU and VUmc approved the study.

\section{Statistical analyses}

Changes over time in treated adults were analysed with univariate paired-sample $t$ tests, applying the Bonferroni correction [dividing the number of tests (19) by $5 \%$ ] and using a significance level of 0.003 for these results (Table 2). Post-operative Sex (MF v. FM) and Subtype (homosexual $v$. non-homosexual) differences were studied with univariate or multivariate analyses of variance [(M)ANOVAs] (Table 3). Nominal or ordinal data were analysed per item with the $\chi^{2}$ test or Mann-Whitney $U$ test respectively.

To identify which factors predicted eligibility for hormone treatment and premature dropout, logistic regression analyses were performed with group membership as the criterion variable (no-starter and starter, completer and drop-out respectively). Since we had no a priori hypotheses about group prediction, the first (stepwise) analysis included all 17 factors: age, sex, sexual orientation, onset age of gender dysphoria, GID symptoms in childhood, gender dysphoria at assessment, social support, body dissatisfaction (3 scales), physical appearance, and psychological functioning (2 tests: 1 and 5 scales). Next, we conducted a (simultaneous) logistic regression analysis using the significant predictors. In case of unequal sample sizes cut values were reset to achieve the highest sensitivity and specificity. 
Table 2. Pre-test and post-test scores of the adult follow-up sample

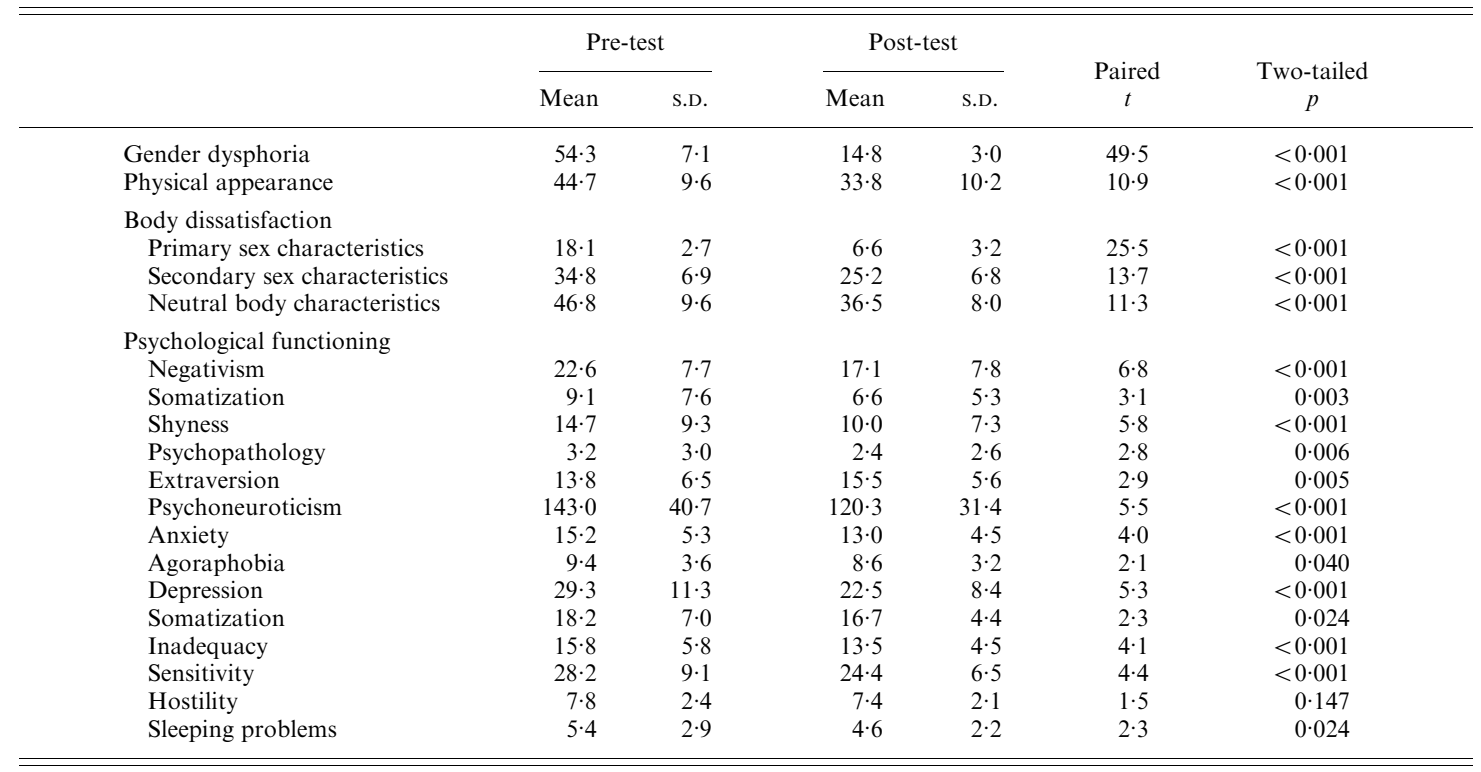

Table 3. Differences between the adult sexes and subtypes at follow-up

\begin{tabular}{|c|c|c|c|c|c|c|}
\hline & $\begin{array}{c}\text { MFs } \\
{[\text { mean (s.D.)] }}\end{array}$ & $\begin{array}{c}\text { FMs } \\
{[\text { mean (S.D.)] }}\end{array}$ & $\begin{array}{c}\text { HOs } \\
{[\text { mean (s.D.)] }}\end{array}$ & $\begin{array}{c}\text { NHs } \\
\text { [mean (s.D.)] }\end{array}$ & $\begin{array}{l}\text { Sex } \\
F(p)\end{array}$ & $\begin{array}{c}\text { Subtype } \\
F(p)\end{array}$ \\
\hline Age & $38 \cdot 6(12 \cdot 3)$ & $29 \cdot 6(8 \cdot 3)$ & $31.7(10 \cdot 7)$ & $39 \cdot 6(11 \cdot 7)$ & $16 \cdot 0(<0 \cdot 001)$ & $6 \cdot 4(0 \cdot 01)$ \\
\hline Gender dysphoria & $15 \cdot 4(3 \cdot 1)$ & $13 \cdot 9(2 \cdot 8)$ & & & $6.6(0.01)$ & $1 \cdot 3(0 \cdot 27)$ \\
\hline Physical appearance & $38 \cdot 2(9 \cdot 3)$ & $26 \cdot 0(6 \cdot 9)$ & & & $28 \cdot 3(<0 \cdot 001)$ & $2 \cdot 0(0 \cdot 16)$ \\
\hline Body dissatisfaction & & & & & $3 \cdot 1(0.03)$ & $1.2(0.33)$ \\
\hline Primary sex characteristics & $6 \cdot 0(2 \cdot 2)$ & $7 \cdot 6(4 \cdot 2)$ & & & $7 \cdot 0(0 \cdot 01)$ & \\
\hline Dutch Short MMPI & & & & & $2 \cdot 1(0 \cdot 07)$ & $2 \cdot 2(0 \cdot 06)$ \\
\hline Somatization & & & $5 \cdot 6(4 \cdot 8)$ & $7 \cdot 9(5 \cdot 5)$ & & $4 \cdot 0(0 \cdot 047)$ \\
\hline Extraversion & $13 \cdot 8(5 \cdot 4)$ & $18 \cdot 0(5 \cdot 0)$ & $17 \cdot 1(5 \cdot 3)$ & $13 \cdot 6(5 \cdot 4)$ & $9 \cdot 2(0 \cdot 003)$ & $6.9(0 \cdot 01)$ \\
\hline Symptom Check List & & & & & $2 \cdot 4(0 \cdot 02)$ & $2 \cdot 6(0 \cdot 009)$ \\
\hline Depression & $24 \cdot 6(9 \cdot 8)$ & $19 \cdot 7(4 \cdot 7)$ & & & $6.5(0.01)$ & \\
\hline Somatization & & & $15 \cdot 2(3 \cdot 7)$ & $18 \cdot 2(4 \cdot 7)$ & & $11 \cdot 0(0 \cdot 001)$ \\
\hline Sleeping problems & & & $4 \cdot 3(2 \cdot 0)$ & $5 \cdot 0(2 \cdot 3)$ & & $5 \cdot 2(0 \cdot 02)$ \\
\hline
\end{tabular}

MFs, male-to-female transsexuals; FMs, female-to-male transsexuals; HOs, homosexual transsexuals; HNs, non-homosexual transsexuals.

Predictors of post-operative functioning were identified with a multiple linear regression analysis with the Post-operative Functioning Scale as the dependent variable. Seven of the 17 factors were relatively independent and included as predictors in the first (stepwise) analysis: sex, sexual orientation, physical appearance, secondary sex characteristics, extroversion, psychopathology, and psychoneuroticism. Patients with missing values were deleted listwise. Significant predictors were analysed in a second (simultaneous) multiple linear regression.

\section{RESULTS}

\section{Outcomes of the adult transsexuals}

\section{Biographical data}

The mean age of the transsexuals who completed SR was 30.9 years (range $17 \cdot 7-68 \cdot 1$ years) at application and $35 \cdot 2$ years (range 21.3-71.9 years) at follow-up. Cross-sex hormone treatment started at the mean age of 31.6 years (range 17.9-68.3 years). The average duration between starting hormone treatment and surgery was $20 \cdot 4$ months (range 12-73 months). The 
average duration between surgery and follow-up was $21 \cdot 3$ months (range 12-47 months).

At follow-up, main effects for Sex and Subtype were found for age. FMs and homosexuals were younger than MFs and non-homosexuals respectively (Table 3 ).

At follow-up 5 subjects $(4.9 \%)$ were students, $38(36.9 \%)$ had jobs, $3(1.9 \%)$ had retired, and $58(56 \cdot 3 \%)$ were unemployed. The majority $(n=59)$ lived independently $(56 \cdot 2 \%), 27$ subjects $(25 \cdot 7 \%)$ each lived together with another adult with or without children, $9(8.6 \%)$ were living with (one of) their parents, $2(1.9 \%)$ were head of an incomplete family, and the remaining $8(7 \cdot 6 \%)$ lived in a guest house or boarding house.

Gender dysphoria. At follow-up there was less gender dysphoria; the low post-test scores represent a virtual absence of gender dysphoria after SR (Table 2). A main effect of Sex was found with FMs feeling less gender dysphoric. No Subtype difference in post-operative gender dysphoria was found (Table 3 ).

Body dissatisfaction. The majority $(n=98$, $91 \cdot 6 \%$ ) were (very) satisfied with their overall appearance; $9(8.4 \%)$ were neutral; no one was dissatisfied. Satisfaction with primary sex, secondary sex, and neutral characteristics had increased after SR (Table 2). A MANOVA showed that FMs were more dissatisfied with their primary sex characteristics at post-test than MFs. No Subtype differences were found (Table 3).

Physical appearance. The group scored lower on the Appraisal of Appearance Inventory at post-test (Table 2), indicating that their appearance better matched the new gender. The physical appearance of FMs was more compatible than that of the MFs, but there was no Subtype difference (Table 3).

Psychological functioning. At follow-up the group functioned psychologically better. Scores on Negativism and Shyness had improved. Scores on Somatization, Psychopathology, and Extroversion showed a tendency towards improvement $(p \leqslant 0 \cdot 006)$. In general, follow-up scores indicated fewer psychological problems
(Table 2). Comparing pre- and post-test group means with Dutch normative data, most scores remained within the average range at follow-up, although Extroversion scores were below average. Somatization scores were high at pre-test.

The mean Psychoneuroticism score was lower after SR [see Table 2 for lower scores on four of the eight subscales $(p<0 \cdot 001)]$. These scores can only be compared with Dutch normative data for males and females separately. Both the MF $(p=0.001)$ and $\mathrm{FM}(p<0 \cdot 001)$ group showed improvement in mean scores. The MFs went from above average at pre-test $($ mean $=143$, S.D. $=38.0)$ to average at post-test (mean $=123$, S.D. $=36 \cdot 0)$; the FMs went from high (mean $=$ 143 , s.D. $=44.8)$ to above average at follow-up $($ mean $=116$, S.D. $=22 \cdot 8)$.

The Dutch Short MMPI showed a marginally significant Sex effect, with FMs being more extrovert. The Sex effect on the Symptom Check List showed MFs as being more depressed than FMs (Table 3). There was also a marginally significant Subtype effect on the Dutch Short MMPI, with homosexuals scoring more favourably on Somatization and Extroversion. The Symptom Check List showed a Subtype effect with homosexuals scoring lower on Sleeping Problems and Somatization (Table 3 ).

Thus, although the group as a whole functioned psychologically rather well at application, their psychological stability had improved after SR. In addition, and post-operatively, FMs and homosexuals functioned psychologically better than MFs and non-homosexuals respectively.

Treatment evaluation and post-treatment functioning. The vast majority $(98.4 \%)$ expressed no regrets about SR. One non-homosexual MF had experienced such strong regrets during and after treatment that she would not elect for SR again, if given a second opportunity. In contrast, a second non-homosexual MF, who expressed some regrets, reported she would choose SR again. Five non-homosexuals (4 MFs, 1 FM) reported some regrets during treatment only, but expressed no desire or intention to resume their original gender role. No differences were found between the sexes in reported regret during $(Z=-1 \cdot 4, p=0 \cdot 2)$ or after SR $(Z=-1 \cdot 1, p=0 \cdot 3)$. During treatment more non-homosexuals reported feelings of regret $(Z=-3 \cdot 1, p=0 \cdot 002)$. 
Social life and social contacts. The majority $(n=90,89 \cdot 1 \%)$ felt accepted by most people, 8 $(7 \cdot 9 \%)$ by some, $3(3 \%)$ by no one. Altogether 84 individuals $(83.2 \%)$ felt supported in their new gender role by (almost) everyone they knew, whereas $11(10.9 \%)$ felt supported by some people. Despite the fact that 6 subjects $(5.9 \%)$ did not feel supported, they were able to rely on some individuals during difficult times. Four subjects $(3.9 \%)$ had no one to turn to when times got hard. Still, the vast majority $(99,96 \cdot 1 \%)$ could rely on at least some others during difficult times. In total, 18 individuals $(17 \cdot 3 \%)$ sometimes felt they were being laughed at, $2(1.9 \%)$ had experienced being ridiculed by strangers; $84(80 \cdot 8 \%)$ had never experienced any such adverse reactions. Over $98 \%(n=102)$ felt they were completely taken seriously by most people. Two $(1.9 \%)$ only felt taken seriously by a few close friends. No one reported not being taken seriously by anyone.

MFs and FMs felt equally accepted $(Z=-0 \cdot 8, p=0 \cdot 4)$. However, FMs had more support in the new gender role $(Z=-2 \cdot 5$, $p=0.01)$ and were more able to rely on significant others during difficult times $(Z=-2 \cdot 2$, $p=0.03)$. Although MFs were more often laughed at or ridiculed $(Z=-3.5, p<0.001)$, they reported feeling taken equally seriously by (almost) all people $(Z=-1 \cdot 7, p=0 \cdot 08)$. Homosexuals felt more supported $(Z=-2 \cdot 0, p=0 \cdot 04)$ and taken more seriously than non-homosexuals $(Z=-2 \cdot 5, p=0 \cdot 01)$.

Relationships and sexuality. The majority $(n=$ $46,88 \cdot 5 \%$ ) of the 50 subjects who had a steady sexual partner were satisfied with their sex life, 3 $(5.8 \%)$ expressed a neutral view, and $3(5.8 \%)$ were dissatisfied. Of the 84 subjects $(82.4 \%$ of the follow-up sample) who were sexually active, the majority $(53,63 \cdot 1 \%)$ achieved orgasm always or regularly, $16(19 \%)$ sometimes, and 15 $(17 \cdot 9 \%)$ never.

A larger percentage $\left(\chi^{2}=4 \cdot 2, p=0.04\right)$ reported a homosexual $(94,58.0 \%)$ than a nonhomosexual orientation $(68,42 \cdot 0 \%)$. Within the FMs a greater proportion $\left(\chi^{2}=5.9, p=0.015\right)$ had a homosexual orientation $(70.7 \%)$ than the MFs $(51 \cdot 0 \%)$. More of the sexually active FMs $(81.6 \%)$ than of the MFs $(42.1 \%)$ achieved orgasm always or regularly $(Z=-2 \cdot 4, p=0 \cdot 01)$.
Yet, both sexes reported equal satisfaction with their sex life $(Z=-0 \cdot 6, p=0 \cdot 5)$. No Subtype differences were found.

Satisfaction with surgery. For FMs breast removal is emotionally the most important surgery. They are advised to postpone metaidoioplasty (transformation of the hypertrophic clitoris into a micropenis) or phalloplasty in view of the fact that surgical techniques are steadily improving. Eleven FMs $(28.9 \%)$ were satisfied with their breast removal, $5(13 \cdot 2 \%)$ were dissatisfied due to the visibility of the scars, and $22(57.9 \%)$ were not completely satisfied. Four FMs were satisfied with their metaidoioplasty or phalloplasty. One FM was dissatisfied because of urinary problems, while four were not completely satisfied.

For the MFs vaginoplasty is the most important surgical intervention. The majority of MFs (47, 70.1\%) were satisfied; $15(22 \cdot 4 \%)$ were not completely satisfied, mostly because they considered their vagina not deep or feminine enough. Five MFs ( $7 \cdot 5 \%$ ) were dissatisfied, because they were unable to achieve sexual arousal or orgasm, or because corrective surgery was needed. The majority $(34,65 \cdot 4 \%)$ were satisfied with their breast augmentation; 15 $(28 \cdot 8 \%)$ were not completely satisfied, and three felt uneasy about their breasts being too far apart.

\section{Predictors of the course and outcomes of adolescent and adult transsexuals}

\section{Prediction of eligibility criteria}

Eligibility for SR was largely based upon the factors gender dysphoria, psychoneuroticism, and physical appearance. For the precise weight of each predictor variable and the constant in this equation model, see Table 4. Stronger gender dysphoria (higher scores), more psychological stability (lower scores on Psychoneuroticism), and a feminine look for MFs and a masculine look for FMs (lower scores on physical appearance), increased the probability of the clinician referring the applicant to start hormone treatment. With these three predictor variables $78 \%$ of the applicants were correctly assigned to the 'no-starter' $(52 \%)$ or the 'starter' $(88 \%)$ group (cut value $=0.63)$. 
Table 4. B coefficients and constants of the factors predicting group membership

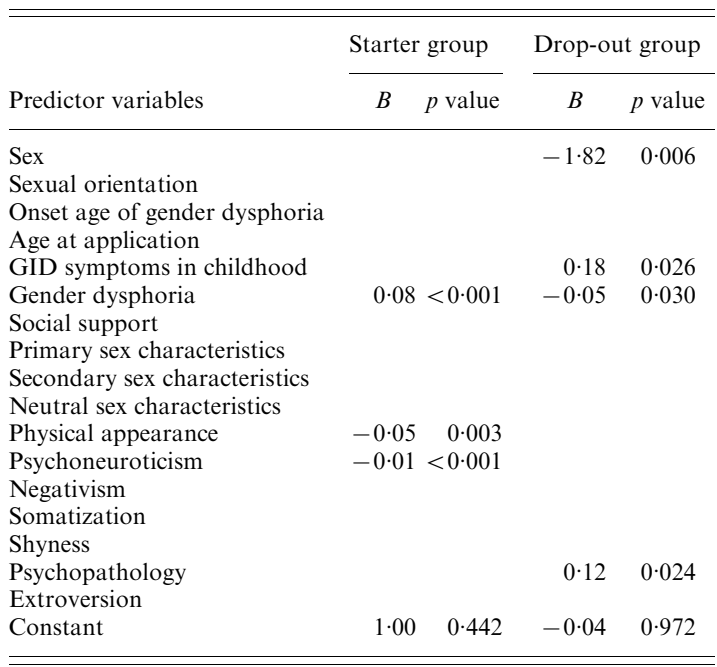

\section{Prediction of the course of treatment}

The probability that a transsexual discontinued hormone treatment depended on sex, psychopathology, childhood GID symptoms, and gender dysphoria (Table 4). A negative coefficient means that a factor contributes negatively to the probability of being a drop-out. The relatively high beta value of the factor sex reflects being a FM. Thus, the combination of being a MF with more psychopathology and childhood GID symptoms, yet less gender dysphoria at assessment, increased the likelihood of premature drop-out. Together these four predictors correctly assigned $68 \%$ of the transsexuals to the 'completer' $(68 \%)$ or the 'drop-out' (69\%) group (cut value $=0 \cdot 15$ ).

\section{Prediction of post-operative functioning}

The level of post-operative functioning could be predicted by the patient's sexual orientation, psychological stability, and dissatisfaction with secondary sex characteristics at assessment. The beta weights (see Beta column in Table 5) show the relative importance of the variables contributing to the predictability of the quality of post-operative functioning $\left(R^{2}=0 \cdot 17\right)$. As higher scores on the Post-operative Functioning Scale reflect more dysfunction and dissatisfaction, the predicted score of an applicant on this scale increased with a non-homosexual
Table 5. Factors predicting post-operative functioning

\begin{tabular}{lrrr}
\hline \hline Model & \multicolumn{1}{c}{$B$} & \multicolumn{1}{c}{ Beta } & \multicolumn{1}{c}{$p$ value } \\
\hline Sexual orientation & $-3 \cdot 70$ & -0.24 & 0.002 \\
Psychopathology & 0.43 & $0 \cdot 17$ & 0.028 \\
Dissatisfaction secondary & 0.31 & 0.28 & $<0.001$ \\
sex characteristics & 16.80 & & $<0.001$ \\
Constant & & & \\
\hline \hline
\end{tabular}

orientation, more psychopathology and dissatisfaction with secondary sex characteristics at assessment.

\section{DISCUSSION}

One aim of this prospective study was to investigate which areas of functioning improve as a consequence of SR. The main symptom for which the patients had requested treatment, gender dysphoria, had decreased to such a degree that it had disappeared. Satisfaction of the patients with their sex characteristics had improved to the point of content, confirming previous results (Green \& Fleming, 1990; Pfäfflin \& Junge, 1998), and according to observers, their appearance better matched the new gender. Psychological functioning had also improved (see Mate-Kole et al. 1990). Thus, it seems safe to conclude that the transsexuals had improved in important areas of functioning and that 1-4 years after surgery, SR appeared therapeutic and beneficial. Furthermore, the vast majority expressed no regrets about their SR.

Post-operative evaluation showed that the majority functioned quite well socially. A small minority, however, lacked support and acceptance, and were ridiculed. Surprisingly, $98 \%$ felt taken seriously. This somewhat rose-coloured view may be explained by the fact that the social support received and the relief about the new situation may have put adverse reactions into perspective, whereas disappointing experiences may have been played down to reduce cognitive dissonance after undergoing such invasive and irreversible interventions.

At follow-up, the majority were content with their sex life, and those who were sexually active, reported achieving orgasm. This has been reported previously (e.g. Rakic et al. 1996; Rehman et al. 1999), but in MFs the capacity 
for orgasm has been reported to decrease postsurgically (Lief \& Hubschman, 1993).

The findings support the conclusion that after SR most transsexuals functioned socially and sexually well. One MF expressed deep regrets. She indicated that professional guidance regarding adverse consequences (i.e. intolerance of society, family and her own children), would have made the transition more endurable. This stresses the need for good aftercare.

Comparing the sexes, the FMs showed better results, supporting the results of earlier studies (see Introduction). This might be due to their more convincing gender role behaviour and looks and their 'type' of transsexualism, implying an earlier age at application. More FMs than MFs were capable of achieving orgasm. This can be attributed to hormonal effects (van Goozen et al. 1995) or to the fact that most FMs lived with their enlarged clitoris. Then again, it may also portray different meanings of sexuality in males and females, since both sexes reported equal satisfaction with their sex life. Contrasting most of the more favourable FM findings are the greater reported satisfaction of the MFs with surgical results. This is understandable given that most FMs did not (yet) have a penis. For the FMs the ability to live in the new gender and sexual role clearly awaits the advancement of surgical techniques.

With respect to subtype differences, homosexuals were younger and functioned psychologically better than non-homosexuals. No differences were found in gender dysphoria, body dissatisfaction, or physical appearance. Only non-homosexuals reported some regrets during treatment, and two during and after SR, which they all related to a lack of acceptance and support from others. The better functioning of homosexuals may also be explained by their sexual orientation. Subtype differences could reflect different aetiological backgrounds. Because the onset age and age at application have been found to be earlier in homosexuals, it is likely that non-homosexuals encounter more problems in life before applying for SR. Also, post-surgically, 'homosexuals' will have opposite gender partners, thus forming heterosexual couples. This still is socially more acceptable.

The less favourable outcomes of the nonhomosexuals carry significant implications for clinical practice. If considered eligible for SR, non-homosexuals should be able to receive additional guidance in coping with adverse consequences, such as a more troubled psychological functioning, or a more critical environment.

In conclusion, our data substantiate findings from mostly retrospective follow-up studies that $\mathrm{SR}$ is effective. Some individuals probably need a more thorough diagnostic procedure and more therapeutic support, sometimes even after treatment, than is currently the case. For most transsexuals in this study, the strict eligibility criteria and professional guidance as currently provided appears to be sufficient, as reflected by the overall favourable outcomes of SR. However, alleviation of the gender problem is not equivalent with an easy life. Apparently, clinicians need to be alert for signs that a transsexual applicant will not be able to cope with adversities during treatment.

Another goal was to identify predictors of the course and outcomes of SR. We found that clinicians assessed applicants to be eligible for hormone treatment when they were more gender dysphoric, psychologically more stable, and when the physical appearance better matched the new gender role. Given the nature of the problem, it is not surprising that strong gender dysphoria was one of the main predictors. Since an unfavourable physical appearance could be a risk factor for post-operative regret (Wålinder et al. 1978), it is interesting to observe that the clinicians also took this factor into account when deciding upon referral. Furthermore, clinicians greatly valued the applicant's psychological functioning (see also Kuiper \& CohenKettenis, 1998). These factors predicted $88 \%$ of the starter group. Clearly, clinicians must have had other reasons for referring the remaining $12 \%$, the most likely factor being the diagnosis. They might also have appraised certain risk factors as relatively harmless in view of existing protective factors (e.g. strong social support, adequate coping skills).

We found transsexuals to be more at risk for dropping out of treatment when they were MFs, showed more psychopathology, more GID symptoms in childhood, yet less gender dysphoria at application. The greater vulnerability of MFs to drop out is understandable given that FMs fare better post-operatively. 
Unfortunately, our data do not permit us to distinguish during treatment between the impact of psychopathology, on the one hand, and of interactive effects of psychopathology with external forces, on the other. We cannot rule out the possibility that it is not psychopathology per se that increases the probability to drop out, but rather a combination of psychological vulnerability and personal circumstances, such as abandonment by a partner. One should also bear in mind that the drop-outs stopped hormone treatment during our data collection; it is possible, however, that they will reapply later in life.

Our finding of an association between more childhood GID symptoms and greater drop out seems puzzling. It is in contrast with the literature on SR risk factors and clinically counter-intuitive. Early gender dysphoria has been associated with early-onset transsexualism and favourable SR outcome (see Lothstein, 1982; Blanchard, 1985; Lindemalm et al. 1987; Blanchard et al. 1989; Pfäfflin, 1992). Here, it is the combination of factors that is crucial. Still, the contradicting presence of more gender dysphoria in childhood but less at application should alert the clinician when assessing eligibility. This inconsistency may reflect confusion about development, an (unconscious) exaggeration of history if current feelings are not clear-cut, or a conscious effort to mislead the clinician.

Finally, we investigated which assessment factors predicted post-operative functioning. It is important to bear in mind that we applied a continuous scale from good to bad, as opposed to the dichotomy 'no regret'-'regret', because hardly any transsexuals reported regret. A nonhomosexual orientation, with more psychopathology and dissatisfaction with secondary sex characteristics predicted unfavourable postoperative functioning. The finding that nonhomosexuals and those with more psychological instability are at risk for unfavourable functioning and more dissatisfaction after SR fits with earlier studies (see Introduction; Blanchard et al. 1989; Landén et al. 1998). We found that two non-homosexuals expressed regret about SR. Finally, dissatisfaction with appearance predicted poor post-operative functioning, either because it directly and adversely affected psychological stability or mood, or it indirectly affected the way they were socially treated (or a combination of both).

Taking all the findings into account, our 'sample' of clinicians appropriately assessed some risk factors that predict the course and outcomes of SR, yet they underestimated others. They particularly recognized the impact of the applicant's psychological functioning and physical appearance on post-operative functioning. However, clinicians might want to take special notice of MFs who report inconsistencies in past and present gender dysphoria, in the presence of psychopathology, and of nonhomosexuals with strong dissatisfaction about their appearance and clear psychopathology. They may benefit from additional guidance after SR, while adjusting to their new lives and coping with unexpected or adverse consequences.

The results of this study subscribe to the significance of some of the risk factors described in the literature with more conclusive data. Furthermore, factors were found that could assist clinicians in identifying individuals who might be at risk for poor outcome.

\section{ACKNOWLEDGEMENTS}

The authors thank Mrs W. Harmsen and $\mathrm{Mr}$ Jos Megens in particular for their invaluable help in the data collection process and appreciate the contribution of Dr Anton M. Verschoor in the setting up of this research project. This work was financially supported by the Stichting Fondsenwervingsacties, the Ziekenfondsraad, and the Stichting Nederlands Gender Centrum.

\section{DECLARATION OF INTEREST}

None.

\section{NOTE}

An Appendix accompanies this paper on the Journal's website (http//journals.cambridge. org).

\section{REFERENCES}

APA (1994). Diagnostic and Statistical Manual of Mental Disorders (4th edn). American Psychiatric Association: Washington, DC. Arrindell, W. A. \& Ettema, J. H. M. (1986). SCL-90: Handleiding bij een multidimensionele psychopathologie-indicator [SCL-90, Manual 
of a multidimensional psychopathology-indicator]. Swets en Zeitlinger: Lisse, The Netherlands.

Blanchard, R. (1985). Typology of male-to-female transsexualism. Archives of Sexual Behavior 14, 247-261.

Blanchard, R., Steiner, B. W., Clemmensen, L. H. \& Dickey, R. (1989). Prediction of regrets in postoperative transsexuals. Canadian Journal of Psychiatry 34, 43-45.

Cohen-Kettenis, P. T. \& Gooren, L. J. G. (1999). Transsexualism: a review of etiology, diagnosis and treatment. Journal of Psychosomatic Research 46, 315-333.

Cohen-Kettenis, P. T. \& van Goozen, S. H. M. (1997). Sex reassignment of adolescent transsexuals: a follow-up study. Journal of the American Academy of Child and Adolescent Psychiatry 36, 263-271.

Day, P. (2002). Tech Brief Series: trans-gender reassignment surgery. New Zealand Health Technology Assessment Report 1, 1-38.

Derogatis, L. R., Lipman, R. S. \& Covi, L. (1973). SCL-90: an outpatient psychiatric rating scale-preliminary report. Psychopharmacology Bulletin 9, 13-27.

Doorn, C. D., Kuiper, A. J., Verschoor, A. M. \& Cohen-Kettenis, P. T. (1996). Het verloop van de geslachtsaanpassing: Een 5-jarige prospectieve studie [The course of sex reassignment: A 5-year prospective study]. Report for the Dutch National Health Council.

Doorn, C. D., Poortinga, J. \& Verschoor, A. M. (1994). Cross-gender identity in transvestites and male transsexuals. Archives of Sexual Behavior 23, 185-201.

Eldh, J., Berg, A. \& Gustafsson, M. (1997). Long-term follow up after sex reassignment surgery. Scandinavian Journal of Plastic and Reconstructive Surgery and Hand Surgery 31, 39-45.

Green, R. \& Fleming, D. (1990). Transsexual surgery follow-up: status in the 1990s. Annual Review of Sex Research 1, 163-174.

Kuiper, A. J. (1991). Transseksualiteit: Evaluatie van de geslachtsaanpassende behandeling [Transsexualism: An evaluation of sex reassignment]. Elinkwijk: Utrecht, The Netherlands.

Kuiper, A. J. \& Cohen-Kettenis, P. T. (1998). Gender role reversal among postoperative transsexuals. International Journal of Transgenderism 2 (http://www.symposion.com/ijt/ijtc0502.htm).

Landén, M., Wålinder, J., Hambert, G. \& Lundström, B. (1998). Factors predictive of regret in sex reassignment. Acta Psychiatrica Scandinavica 97, 284-289.

Lawrence, A. A. (2003). Factors associated with satisfaction or regret following male-to-female sex reassignment surgery. Archives of Sexual Behavior 32, 299-315.

Lief, H. \& Hubschman, L. (1993). Orgasm in the postoperative transsexual. Archives of Sexual Behavior 22, 145-155.

Lindemalm, G., Körlin, D. \& Uddenberg, N. (1987). Prognostic factors vs. outcome in male-to-female transsexualism: a follow up of 13 cases. Acta Psychiatrica Scandinavica 74, 268-274.

Lindgren, T. \& Pauly, I. (1975). A body image scale for evaluating transsexuals. Archives of Sexual Behavior 4, 639-656.

Lothstein, L. M. (1982). Sex reassignment surgery: historical, bioethical, clinical and theoretical issues. American Journal of Psychiatry 139, 417-426.

Lundström, B., Pauly, I. \& Wålinder, J. (1984). Outcome of sex reassignment surgery. Acta Psychiatrica Scandinavica 70, 289-294.

Luteyn, F., Kok, A. R. \& van der Ploeg, F. A. E. (1980). NVM, Nederlandse verkorte MMPI, Handleiding [Dutch short version of the Minnesota Multiphasic Personality Inventory, Manual]. Swets en Zeitlinger: Lisse, The Netherlands.
Mate-Kole, C., Freschi, M. \& Robin, A. (1990). A controlled study of psychological and social change after surgical gender reassignment in selected male transsexuals. British Journal of Psychiatry 157, 261-264.

Meyer III, W., Bockting, W. O., Cohen-Kettenis, P. T., Coleman, E., DiCeglie, D., Devor, H., Gooren, L. J. G., Hage, J. J., Kirk, S., Kuiper, A. J., Laub, D., Lawrence, A., Menard, Y., Patton, J., Schaefer, L., Webb, A. \& Wheeler, C. C. (2001). The standards of care for gender identity disorders (6th Version). International Journal of Transgenderism 5 (http://www.symposion.com/ijt/soc/ index.htm).

Molenaar, I. W. (1982). Mokken scaling revisited. Kwantitatieve methoden 3, 145-164.

Pfäfflin, F. (1992). Regrets after sex reassignment surgery. Journal of Psychology \& Human Sexuality 5, 69-85.

Pfäfflin, F. \& Junge, A. (1992). Geschlechtsumwandlung: Abhandlungen zur Transsexualität. Schattauer: Stuttgart, Germany.

Pfäfflin, F. \& Junge, A. (1998). Sex Reassignment: Thirty years of international follow-up studies SRS: A Comprehensive Review, 1961-1991 (English edn). Symposion Publishing: Düsseldorf, Germany (http://www.symposion.com/ijt/pfaefflin/1000.htm).

Rakic, Z., Starcevic, V., Maric, J. \& Kelin, K. (1996). The outcome of sex reassignment surgery in Belgrade: 32 patients of both sexes. Archives of Sexual Behavior 25, 515-525.

Rehman, J., Lazer, S., Benet, A., Schaefer, L. \& Melman, A. (1999). The reported sex and surgery satisfactions of 28 postoperative male-to-female transsexual patients. Archives of Sexual Behavior 28, 71-89.

Ross, M. W. \& Need, J. A. (1989). Effects of adequacy of gender reassignment surgery on psychological adjustment: a follow-up of fourteen male-to-female patients. Archives of Sexual Behavior 18 $145-153$.

Spengler, A. (1980). Kompromisse statt stigma und unsicherheit. Transsexuelle nach der operation [Compromises instead of stigma and doubts. Transsexuals after surgery]. Sexualmedizin $\mathbf{9}$, 98-103.

Smith, Y. L. S., Cohen, L. \& Cohen-Kettenis, P. T. (2002). Postoperative psychological functioning of adolescent transsexuals: a Rorschach study. Archives of Sexual Behavior 31, 255-261.

Smith, Y. L. S., van Goozen, S. H. M. \& Cohen-Kettenis, P. T. (2001). Adolescents with gender identity disorder who were accepted or rejected for sex reassignment surgery: a prospective follow-up study. Journal of the American Academy of Child and Adolescent Psychiatry 40, 472-481.

van Goozen, S. H. M., Cohen-Kettenis, P. T., Gooren, L. J. G., Frijda, N. H. \& van de Poll, N. E. (1995). Gender differences in behavior: activating effects of cross sex hormones. Psychoneuroendocrinology 20, 343-363.

Van Tilburg, T. (1988). Verkregen en gewenste ondersteuning in het licht van eenzaamheidservaringen [Received and desired support related to the experience of loneliness]. Elinkwijk: Utrecht, The Netherlands.

Verschoor, A. M. \& Poortinga, J. (1988). Psychosocial differences between Dutch male and female transsexuals. Archives of Sexual Behavior 17, 173-178.

Wålinder, J., Lundström, B. \& Thuwe, I. (1978). Prognostic factors in the assessment of male transsexuals for sex reassignment. British Journal of Psychiatry 132, 16-20. 